\title{
Arqueologia, Memória e Patrimônio. A Iconografia e o Estudo da História
}

\author{
Archeology, Memory and Heritage. Iconography and the Study \\ of History
}

\section{Resumo:}

Nesse artigo, realizaremos uma análise da imagem como fonte documental para o estudo da arquitetura e história, através de um estudo imagético de Villefranche de Conflent, pequena vila medieval francesa, candidata a patrimônio mundial pela Unesco, considerada uma das mais belas e conservadas vilas medievais da Europa Ocidental.

Palavras-Chaves: Memória, Patrimônio, Arqueologia,

Abstract:In this article, we analyze the nature of images as documentary sources in the study of architecture and history. The case study presented is an image-based study of Villefranche de Conflent, a medieval French village. This particular village is a candidate for declaration as a UNESCO World Heritage Site, and is considered to be one of the most beautiful and wellpreserved medieval villages in Western Europe.XXX

Key Words: Memory, Heritage, Archaeology

\footnotetext{
${ }^{1}$ Professor Associado I de História Antiga e do Programa de Pós Graduação em História Ibérica (PPGHI) da Universidade Federal de Alfenas / MG.
} 
Introdução: memória

A memória em si, ligada à aprendizagem, ou a uma função e experiência aprendida no passado, faz parte de uma preocupação básica com a sociedade. As exigências da vida em grupo resultam frequentemente na modelagem da memória através da repressão, do enfoque em certas esferas de interesse.

Segundo Leroi-Gourhan, a "memória é entendida,(...) em sentido muito lato. Não é uma propriedade da inteligência, mas a base, seja ele qual for, sobre a qual se inscrevem as concatenações dos atos" (LE GOFF: 1984, 12). Quanto a isto podemos destacar a memória social, na qual designa o caráter social da construção da memória humana: a associação com as questões do tempo e da história, como um meio de identificar e formar as identidades.

Assim, nosso objetivo é o de realizar uma análise tanto da memória social ou coletiva, no sentido da identidade dos grupos, classes, tradição histórica, como também da memória individual, na realização de um fato social. Existindo desta forma uma relação entre memória e o documento.

Le Goff descreve que: "Os materiais da memória podem apresentar-se sob duas formas principais: os monumentos, herança do passado, e os documentos, escolha do historiador". Cabe ao historiador identificar e definir as suas fontes, pois o documento não é inócuo é, segundo o próprio Le Goff, “...uma montagem consciente ou inconsciente, da história, da época, das sociedades que o produziram...esforço para as sociedades históricas para impor ao futuro...determinada imagem de si próprias..." (LE GOFF: 1984, 95).

Nesse sentido, é necessário haver uma interdisciplinaridade para ser realizada uma desmontagem da ambivalência documento/monumento, através do próprio ambiente que o produziu, auxiliado pela arqueologia, e não baseado em uma única crítica histórica.

Ao desmontar as condições de produção documento/monumento nas representações ideológicas na Castela Medieval, Nieto Soria acrescenta que as cerimônias do poder são únicas, e não repetitivas, não se tratando de um discurso 
vazio, pois cada leitura há uma diferente visão. A cerimônia política torna-se mais forte que a retórica escrita, na própria legitimação do poder o ritual esta presente.

\begin{abstract}
"Em efeito, ritos e cerimônias políticas contribuem a estabelecer, confirmar e, as vezes, a transformar as relações de poder existente entre aqueles que protagonizam, porém em níveis distintos, tais acontecimentos, em definitiva, entre os governantes e os governados, por que é possível desvendar, através do estudo dos rituais e cerimoniais, implicações políticas e sociais que caso haviam sido inapreciadas sem ter em conta esse tipo de informação, contribuindo com isto a aumentar substancialmente seu relevo histórico" (NIETO SORIA:1993,16).
\end{abstract}

\title{
Patrimônio e seus Simbolismos
}

A partir da promulgação do Decreto-Lei n. 25, de 30 de novembro de 1937, tanto o patrimônio arqueológico pré-histórico, quanto à arquitetura, estudadas e analisadas nos séculos XIX e XX, do mundo material aos bens intangíveis, esses universos plurais protegidos passaram a ser protegidospor uma legislação genérica e específica.

Não podemos esquecer da crescente importância do patrimônio imaterial, como o Samba, tombado recentemente. Algo novo para nós, mas comum da Europa do pós-guerra. Como a disputa de xadrez em Maróstica (capital mundial do xadrez), que acontece a cada dois anos, no mês de setembro, no nordeste da Itália, ou o drama de Elche, no sul da Espanha, tombado com bem imaterial desde a década de 1980. Ao conhecermos as leis que regem a preservação, será mais fácil defender nossas heranças arqueológicas.

Segundo Dicionário de Ciências Sociais, editado pela Fundação Getúlio Vargas, os símbolos políticos são definidos como símbolos que funcionam até um ponto significativo na prática do poder. Nesse sentido, o ser humano, durante a sua passagem pelo planeta, desenvolveu diversas formas simbólicas, tanto artística, quanto linguística, expressa pela sua consciência. 
A maioria dos padrões técnicos-científicos que conhecemos nasceram no século XIX, seguindo um processo epistemológico, cujo apogeu será depois da Segunda Grande Guerra.

Durante muitos anos, os estudos patrimoniais históricos e arquitetônicos estavam presos ao documento textual. Imperava o historicismo alemão, a ciência era um fruto do rigor físico newtoniano. "Sem documento escrito não existe História", era o lema a ser defendido.

Quando Eugéne Viollet - le - Dux (1814 - 1874), escreve seus primeiros conceitos sobre restauração, ligado a arquitetura revivalista, tanto a preservação do patrimônio, quanto as bases teóricas da arquitetura moderna, foram lançadas. Porém, a ideia de preservação ou de "restauração" é bem mais antiga.

Vários governantes em diversas épocas se preocuparam com os bens do Estado, principalmente ligados à sua pessoa. Ramsés II, terceiro faraó da XIX dinastia, reinou entre aproximadamente 1279 a.C. e 1213 a.C, restaurou vários templos construídos por seus antecessores, acrescentando seu nome aos prédios. Prática essa abominável para nós, mas aceita no Egito Antigo, pois o faraó reinante é o protetor do templo. Diocleaciano, 236 ou 238 - 316, imperador romano e criador do sistema de tetrarquia,restaurou vários monumentos construídos por Augusto, 63 a. C. - 14 a. C., entre eles, o templo de Augusto, no Fórum Romano.

Em resumo, as idéias de Preservação, Restauração, Proteção, manutenção de uma memória coletiva, acompanham a sociedade humana, há vários séculos.

Nesse sentido, o patrimônio histórico e arqueológico é um bem móvel, imóvel ou natural, que possua valor significativo para uma sociedade, podendo ser estético, artístico, documental, científico, social, espiritual ou ecológico. Nas últimas décadas, a Arqueologia tem se preocupado, cada vez mais, com sua dimensão pública. 


\section{Memória e Patrimônio: o exemplo de Villefranche de Conflent}

Essa pequena vila localizada nos Pirineus Orientais, na região de Languedoc Roussillon, famosa pelos seus vinhos, foi fundada pelo Conde de Cerdagne, Guillaume-Raymond, entre os anos de 1090 e 1092. A intenção de Guillaume era transformar Villefranche na capital do seu condado, graças a sua localização estratégica (CARLAN: 2008, s/p).

Não apenas essa Vila, mas toda a região do Languedoc, foi palco das mais sangrentas batalhas e revoltas. Como a de Átila, o huno, contra o "último do romanos", Flávio Aécio (batalha dos campos catalúnicos, 451), a heresia dos cátaros (século XI) e em 1674, a conspiração de Villefranche, no qual algumas famílias da vila tentaram reunificar o território com a Catalunha espanhola. A coroa francesa agiu rapidamente. Os participantes do levante foram torturados e seus corpos expostos em jaulas de ferro, na entrada da cidade.

A batalha entre Átila e Aécio não atingiu, diretamente, a região, mas fechou a entrada dos hunos no Império Romano. Quanto aocatarismo, ou heresia dos cátaros, religião cristã que diferenciava da doutrina do Vaticano. Acreditavam que Jesus não era o filho de Deus, mas um importante profeta, na pobreza do clero e não faziam distinção entre os sexos (CARLAN: 2008, s/p).

O próprio Papa Inocêncio III (1198 - 1216) organizou uma expedição contra a região (chamada de Cruzada Albigense) que durou cerca de 40 anos. O rei Pedro I de Aragão saiu em defesa dos cátaros e morreu em batalha. Carcassonne (restaurada por Viollet - le - Dux) e Villefranche foram destruídas pelo exército papal. Homens, mulheres e crianças foram queimados vivos.

Esta heresia também está ligada as lendas medievais do Santo Graal, sendo a fonte para vários romances modernos como o Código da Vinci, de Dan Brown.

Depois dessas séries de destruições, coube ao engenheiro militar francês, Sébastien Le Preste, Marquês de Vauban (1633 - 1707), realizar algumas obras visando restaurar a antiga fortaleza. Em 1793 foi construído o Forte de Libéria, localizado acima da Vila, no monte Belloc (CARLAN: 2008, s/p). 
Nos últimos anos a iconografia tem sido utilizada como fonte documental em várias áreas das ciências humanas. Através da imagem abaixo, realizaremos uma série de análises, situando a representação no espaço / tempo histórico e arquitetônico.

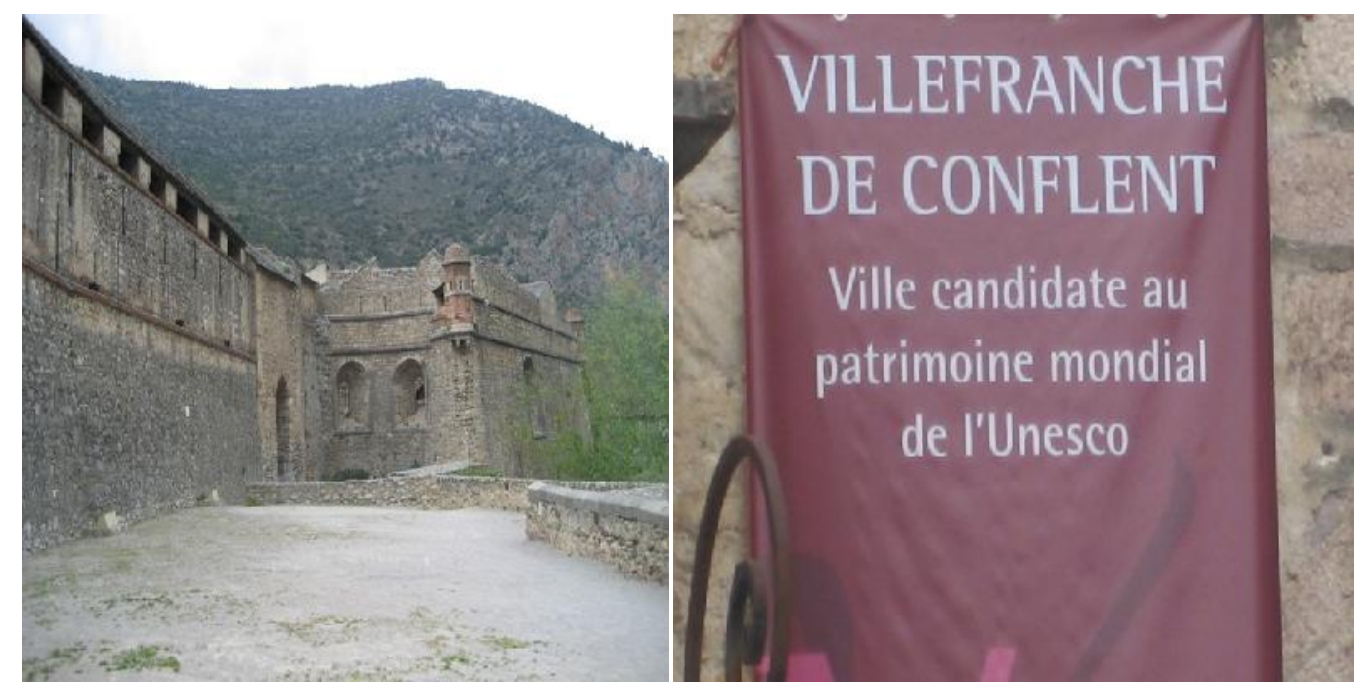

Referência: foto de Cláudio Umpierre Carlan, Maio de 2007.

Antigo pórtico principal de Villefranche, construído entre os séculos XI e XII. Típica construção medieval, com muralha dupla e dois portões (interno e externo), visando à defesa contra as constantes guerras entre os senhores feudais da região. A vila em si está apertada pelas muralhas, ruas estreitas, sem infra-estrutura ou urbanização. Quando chovia as ruas ficavam completamente alagadas (CARLAN: $2008, \mathrm{~s} / \mathrm{p})$. Como não tinham um sistema de esgoto, os detritos eram jogados nas ruas, ampliando o risco das epidemias.

Havia uma ponte levadiça, comum nas cidadelas medievais. Toda essa aérea era cercada pelo rio Têt. A parte de trás da Vila mantém a proximidade com o rio. Vauban construiu uma ponte de pedra no século XVII, ainda utilizada pelos seus 250 habitantes. A parte frontal (na foto) foi aterrada depois da Primeira Guerra Mundial (1914-1918). Hoje, por causa do grande número de turistas, foi transformado em um 
amplo estacionamento. Atualmente, o rio Têt passa a uns 150 metros do pórtico principal.

Ao lado do pórtico eram colocados os prisioneiros em jaulas penduradas nas paredes. Geralmente vivos, ficavam expostos até a decomposição dos corpos, servindo de aviso para os futuros revoltados.

As paredes da muralha foram construídas com os mais variáveis materiais. Pedras, pequenos tijolos de barros, lápide de túmulos, entre outros, revestidos de argamassa. De uma maneira geral segue o padrão romano. A diferença principal é que os romanos usavam grandes pedras retangulares, mais resistentes que as construções medievais (CARLAN: 2008, s/p).

Notamos pequenas aberturas onde os arqueiros lançavam suas flechas em caso de ataque. Na parte de cima, uma proteção para os soldados, reconstruída pro Vauban. Esta proteção em forma de telhas de concreto protegiam a guarnição contra flechas, lanças, pedras e outros objetos lançados pelos exércitos inimigos. Dessa posição, os protetores da cidadela podiam jogar os mais variados objetos nos inimigos, como óleo fervente, pedras, entre outros.

\section{Considerações Finais}

Com o documento imagético podemos analisar não apenas um estilo arquitetônico, mas também um estilo de vida, a riqueza de uma civilização, seus avanços artísticos e tecnológicos, sua ideologia política e religiosa, sua existência.

É dessa fonte que se nutre a Arqueologia e a Cultura Material. Registram a existência de povos nos labirintos da História. Labirintos esses que muitas vezes a documentação escrita não consegue penetrar

Apesar de duramente criticados, com uma certa razão, os historicistas iniciaram um processo sem fim. Trabalharam com uma série de documentos que, infelizmente, não chegaram até os dias atuais. Os achados arqueológicos de Schilemman (Tróia) desapareceram depois da invasão soviética (Berlim, 1945). Como 
os manuscritos maias "sumiram" do Museu de Berlim, sendo encontrados décadas mais tarde em Moscou.

Hoje vivemos algo semelhante. A invasão norte-americana ao Iraque, destruiu, e continua destruindo, o sítio arqueológico de Mossul (antiga Nínive, capital do Império Assírio, maior e um dos mais importante sítio arqueológico do Oriente Médio), além do saque no Museu de Bagdá. Documentos museológicos que, se não foram destruídos, estão em mãos de colecionadores.

Muitos pesquisadores, décadas depois, entre eles o britânico Jenkins, defendem a ideia que História sempre vai servir a um propósito político, seja colaborar para produzir mais substâncias às ideologias, seja legitimar atores e/ou instituições, funcionando, assim, como uma espécie de força legitimadora de um poder público ou de uma doutrina social (JENKINS: 2001, 75).

O autor revela que desde os primeiros impérios, os governantes se preocuparam com os arquivos oficiais, narravam passagens do seu governo e conferiam sentido à sua existência e da coletividade, a exemplo de Hamurábi, Ramsés II, Augusto, Constantino, Carlos Magno, Luís XIV, Napoleão, personagens históricos que revelaram uma grande preocupação com os fatos narrados em seus arquivos.

Em sua análise acerca do poder, Michel Foucault (1979) identifica não a fonte do poder, mas a sua origem genealógica. Segundo ele, essa origem determinaria os chamados "micro-poderes" presentes nas sociedades modernas. Este poder não se caracterizaria por uma noção de classe, nem se situaria unicamente nos campos da economia ou da política, e sim se estabelece em uma complexa rede de forças, presente em todos os aspectos da vida social. Chartier (1990) situa esta discussão em termos de signos do poder, isto é, uma série de monumentos, emblemas, medalhas, moedas que identificariam o Estado, com o objetivo de representar simbolicamente 0 seu poder.

Interpretar é inferir: uma operação lógica por meio da qual, de uma ou mais proposições - no caos presente, os dados estabelecidos ao terminar o processo da análise de conteúdo aplica ao corpus - se retira uma ou mais consequências que resultem necessariamente daquelas proposições. Trata-se aqui, de voltar às hipóteses para, por meio dessa inferência, avaliar até que ponto forma comprovadas. Caso uma 
ou mais hipóteses hajam sido, pelo contrário, refutadas pelos resultados da análise de conteúdo, será preciso verificar a razão de tal coisa ter acontecido e, conforme as circunstância, completar, modificar parcialmente ou substituir as hipóteses em questão; e, a seguir, recomeçar a análise ou pelo menos, introduzir nela as consequências de tais operações.

A imagem como fonte documental começa a ganhar vida. A tese de Fernand Braudel, O mediterrâneo e o mundo mediterrânico, defende um estudo interdisciplinar entre os mais variados gêneros das ciências humanas ou não. Geografia, História, Arquitetura, Arqueologia, Museologia, Literatura outrora inimigas ou rivais, torna-se aliadas.

Em um período, no qual a escrita é um privilégio de poucos, de uma elite, a iconografia transmite uma carga simbólica muito forte. Através desses modelos imagéticos, um governante transmitia a seus governados atos de sua investidura, tratados militares, casamentos, alianças, segurança. Segundo Greimas, o significado do termo "construção", aparece como um sinônimo de "artificial" opondo-se a "natural", uma referência à ação do homem que transforma a natureza.

$\mathrm{Na}$ vila de Villefranche de Conflent conhecemos a memória de uma época. Um período de incertezas, onde a ideologia religiosa do Vaticano era a única lei.Suas pedras narram à História desse povo, simples, analfabeto para os nossos padrões, que acreditavam na igualdade e fraternidade, ideais da futura Revolução Francesa.

Sem misericórdia, o exército papal comandado por Simon de Monfort massacrou e destruiu tudo a sua volta. Muitos dos escritos sobre o catarismo, realizado por clérigos simpatizantes se perdeu. Mas a cidadela ainda está presente, representando não apenas uma época passada, mas as pessoas que ali viveram.

\section{Agradecimento:}

À UFPEL, em especial a amiga e colega Rita Juliana Poloni pela oportunidade de trocarmos ideias; a Pedro Paulo Abreu Funari, Lúcio Menezes; ao apoio institucional da UNIFAL-MG e FAPEMIG. A responsabilidade pelas ideias restringe-se ao autor. 


\section{Referências}

BAYROU Lucien. Entre le Languedoc et le Roussillon, 1258-1659, fortifier une frontière ? Ed. Amis du Vieux Canet, 2004.

BURKE, Peter. Visto y no visto. El uso de la imagen como documento histórico. Barcelona: Crítica, 2005.

CARDOSO, Ciro Flamarion S. e PÉREZ BRIGNOLI, Héctor. Os Métodos da História. 2a.ed. Rio de Janeiro: Editora Graal, 1979.

CARDOSO, Ciro Flamarion S. História do Poder, história política. In: Estudos Ibero-Americanos. v. XXIII. n. 1. Porto Alegre: EDIPUCRS, 1997.

CARLAN, Claudio Umpierre. Numismática / Documento / Arqueologia: a cultura material e o ensino da história. In: Cadernos de História n. 12 / 13. v. 1. Uberlândia: Instituto de História /Centro de Documentação e pesquisa em História / UFU, 2004 / 2005. p. 148.

CARLAN, Cláudio Umpierre. Arquitetura, História e Urbanismo: a imagem como fonte documental. O exemplo de VilleFranche de Conflent. In: Visões Urbanas - Cadernos PPG-AU/FAUFBAVol.V Número Especial - 2008.

CASTELLS, Manuel. Problemas de Investigação em Sociología Urbana. Lisboa: Editorial Presença, s/d.

CHARTIER, Roger. História Cultural. A História Cultural: entre práticas e representações. Rio de Janeiro: Bertrand, 1990.

DICIONÁRIO DE CIÊNCIAS SOCIAIS. Fundação Getúlio Vargas, Instituto de Documentação. Rio de Janeiro: Editora da Fundação Getúlio Vargas, 1987.

FOUCUALT, Michel. Microfísica do Poder. Rio de Janeiro: Graal, 1979.

FUNARI, Pedro Paulo A. A Renovação no Ensino da História Antiga. In: KARNAL, Leandro (org). História em Sala de Aula. São Paulo: Contexto, 2003, p. 96.

FUNARI, Pedro Paulo Abreu. Arqueologia e Patrimônio. Erechim: Habilis, 2007.

FUNARI, Pedro Paulo Abreu e CARLAN, Cláudio Umpierre. Arqueologia Clássica e Numismática. Textos Didáticos n. 62. Campinas: IFCH / UNICAMP, 2007.

GREIMAS, A. J. e COURTÉS, J. Dicionário de Semiótica. São

Paulo: Editora Cultrix, 1979. 
GUARDIA, M.; OYON, Jose Luis; MONCLUS, Francisco. Atlas Histórico de Ciudades Européas. V. I Península Ibérica. Barcelona: Centre de Cultura Contemporânea Barcelona-Salvat, 1994.

JENKINS, Keith. A História Repensada. Tradução de Mario Vilela. Revisão Técnica Margareth Rago. São Paulo: Editora Contexto, 2001.

LE GOFF, Jacques. Memória-História. In: Enciclopédia Einaudi. V.1. Verbetes "História","Memória", "Documento/Monumento". Lisboa: Imprensa Nacional-Casa da Moeda, 1984.

NIETO SORIA, Jose Manuel. Ceremonias de La Realeza. Propaganda y Legitimacion en La Castilla Trastámara. Madrid: Editorial Nerea, 1993. 